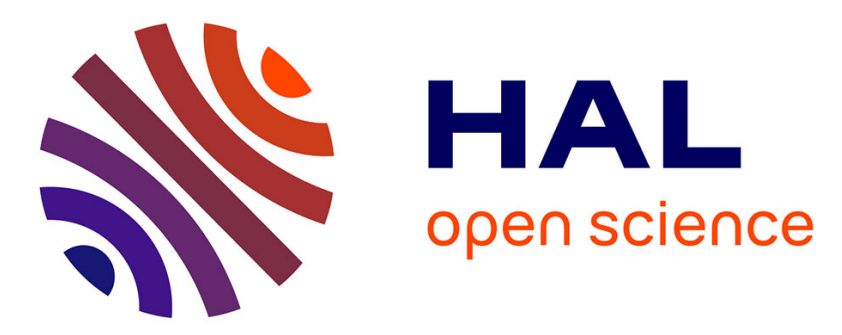

\title{
germline mutations in familial breast cancer cases with personal and family history of pancreatic cancer
}

Paolo Peterlongo, Irene Catucci, Graziella Pasquini, Paolo Verderio, Bernard

Peissel, Monica Barile, Liliana Varesco, Mirko Riboni, Stefano Fortuzzi, Siranoush Manoukian, et al.

\section{To cite this version:}

Paolo Peterlongo, Irene Catucci, Graziella Pasquini, Paolo Verderio, Bernard Peissel, et al.. germline mutations in familial breast cancer cases with personal and family history of pancreatic cancer. Breast Cancer Research and Treatment, 2010, 126 (3), pp.825-828. 10.1007/s10549-010-1305-1 . hal00602983

\section{HAL Id: hal-00602983 \\ https://hal.science/hal-00602983}

Submitted on 24 Jun 2011

HAL is a multi-disciplinary open access archive for the deposit and dissemination of scientific research documents, whether they are published or not. The documents may come from teaching and research institutions in France or abroad, or from public or private research centers.
L'archive ouverte pluridisciplinaire HAL, est destinée au dépôt et à la diffusion de documents scientifiques de niveau recherche, publiés ou non, émanant des établissements d'enseignement et de recherche français ou étrangers, des laboratoires publics ou privés. 


\section{PALB2 germline mutations in familial breast cancer cases with personal and family history of pancreatic cancer.}

Paolo Peterlongo ${ }^{1,2,8}$, Irene Catucci ${ }^{1,2,8}$, Graziella Pasquini ${ }^{2}$, Paolo Verderio ${ }^{3}$, Bernard Peissel ${ }^{4}$, Monica Barile $^{5}$, Liliana Varesco ${ }^{6}$, Mirko Riboni ${ }^{1}$, Stefano Fortuzzi ${ }^{7}$, Siranoush Manoukian ${ }^{4}$, Paolo Radice ${ }^{1,2, \star}$

${ }^{1}$ IFOM, Fondazione Istituto FIRC di Oncologia Molecolare, Milan, Italy.

${ }^{2}$ Unit of Molecular Bases of Genetic Risk and Genetic Testing, Department of Preventive and Predictive Medicine, Fondazione IRCCS Istituto Nazionale dei Tumori, Milan, Italy.

${ }^{3}$ Unit of Medical Statistics and Biometry, Fondazione IRCCS Istituto Nazionale dei Tumori, Milan, Italy.

${ }^{4}$ Unit of Medical Genetics, Department of Preventive and Predictive Medicine, Fondazione IRCCS Istituto Nazionale dei Tumori, Milan, Italy.

${ }^{5}$ Division of Cancer Prevention and Genetics, Istituto Europeo di Oncologia, Milan, Italy.

${ }^{6}$ Unit of Hereditary Cancers, Istituto Nazionale per la Ricerca sul Cancro, Genoa, Italy.

${ }^{7}$ Cogentech, Consortium for Genomic Technologies, Milan, Italy

${ }^{8}$ These authors contributed equally to this work.

${ }^{*}$ Correspondence to Paolo Radice. Unit of Molecular Bases of Genetic Risk and Genetic Testing, Department of Preventive and Predictive Medicine, Fondazione IRCCS Istituto Nazionale dei Tumori, Milan, Italy. E-mail: paolo.radice@istitutotumori.mi.it. Telephone: +39 02.2390.3224. Fax: +39 02.2390 .2764 
To the Editor,

PALB2 (partner and localizer of BRCA2) has been recently described as a breast cancer predisposing gene [1,2]. In the first report, PALB2 truncating mutations were identified in 10/923 (1.1\%) English familial breast cancer cases [1]. Subsequent studies in Spanish, Chinese and Italian familial breast cancer found truncating mutations with frequencies ranging between 0.8 and $1.1 \%$ [36]. Also, PALB2 founder mutations were observed in 2.7\% Finnish [7] and 0.6\% Polish [8] familial breast cancer cases, and in 0.7\% French-Canadian breast cancer cases with early onset disease [9].

Recently, exomic sequencing revealed a germline truncating mutation of $P A L B 2$ in a familial pancreatic cancer case [10]. In the same study, the sequencing of PALB2 in 96 additional familial pancreatic cancer patients, ascertained in the US, identified truncating mutations in three cases. A subsequent larger survey analyzed 254 sporadic and familial pancreatic cancer cases ascertained in Toronto and Montreal, including nine individuals who were also diagnosed with breast cancer, one of which was found to carry a 6.7-kb deletion involving exons 12 and 13 [11]. Interestingly, of the five PALB2 mutated pancreatic cancer cases reported in the above studies, two also developed breast cancer, including one patient with three additional breast cancer cases in the family. Moreover, two of the three remaining cases had $\geq 2$ relatives affected with breast cancer. The last case belonged to a family negative for breast cancer, but the reported pedigree was small and included only one female individual [10]

In this contest, we sought to investigate the frequency of $P A L B 2$ germline pathogenic mutations in index cases from breast cancer families with cases of pancreatic carcinoma. We took advantage of the sequencing of the entire coding region of PALB2 that we performed in 575 Italian female familial breast cancer cases. These were ascertained at the Medical Genetics Units of the Fondazione IRCCS Istituto Nazionale Tumori and the Istituto Oncologico Europeo in Milan, from March 2003 to August 2008. All subjects, therein referred to as BRCAX cases, were probands of families fulfilling previously reported diagnostic criteria for hereditary breast/ovarian cancer, based on family history and age at disease onset [12], and were ascertained not to carry deleterious mutations 
or unclassified variants in $B R C A 1$ or $B R C A 2$ genes, following direct sequencing or denaturing highperformance liquid chromatography (DHPLC) analysis of all coding exons and adjacent splice sites, as previously described [12]. In the 575 BRCAX cases we found 12 carriers of truncating mutations for a frequency of $2.1 \%$. Overall, a total of nine different alterations were detected, of which five were frameshift, three were nonsense and one was a splicing mutation (manuscript in preparation).

Mutations of $P A L B 2$ have been described as having moderate penetrance $[1,2]$, although it was recently suggested that the risk conferred by these mutations may be high in women with strong family histories [13]. While this aspect requires further investigation, we conservatively treated PALB2 mutations as moderate-penetrance factors and, consequently, as expected to show incomplete segregation with the disease [2]. Thus, through pedigrees analysis of the 575 BRCAX families we selected those in which at least one pancreatic carcinoma case was reported by the index case in $1^{\text {st }}$ or $2^{\text {nd }}$-degree relatives, irrespectively of the breast cancer family branch. Whenever possible, the diagnosis of pancreatic carcinoma was confirmed by reviewing medical and pathological reports.

Thirty-nine breast/pancreatic cancer pedigrees were identified, including three families (M1475, M1203 and M1504) carrying PALB2 truncating mutations, namely the c.3497delG (p.Gly1166fs), c.72delG (p.Leu24fs) and c.1027C>T (p.GIn343X) (Figure 1). This frequency of 7.7\% (3/39) suggested that, among breast cancer families, those with cases of pancreatic carcinoma might be enriched in PALB2 mutations. To verify this hypothesis, we examined a second group of 23 probands from breast/pancreatic families selected among additional BRCAX cases, using the same criteria described above, (i.e. female breast cancer cases from families fulfilling diagnostic criteria for hereditary breast/ovarian cancer, who tested negative for BRCA gene mutations and reported $\geq 11^{\text {st }}$ or $2^{\text {nd }}$ degree relatives affected with pancreatic carcinoma). One of these 23 BRCAX cases was affected also with pancreatic cancer. No PALB2 truncating mutations were detected in any of these individuals, leading to an overall frequency in the two combined groups of breast/pancreatic cancer families of 3/62 (4.8\%; exact 95\% confidence Interval = 0.99-13.29). 
In addition, we tested one individual from a family (B276) with multiple cases of cancer to several organs, but not complying with the above inclusion criteria, who developed carcinomas of breast, pancreas, small intestine and colorectum, (Figure 1). In this individual the c.1314delA (p. Lys438fs) truncating mutation was identified.

As already mentioned, previous reports have shown that the majority of familial pancreatic cancer cases with PALB2 germline mutations have a personal and/or family history of breast cancer $[10,11]$. This was recently confirmed by a study, published while this manuscript was in preparation, that analyzed 81 European familial pancreatic cancer cases and identified three carriers of PALB2 truncating mutations, all of whom had $\geq 1$ relative affected with breast cancer [14]. These observations suggested that PALB2 mutations are preferentially associated with families with history of both breast and pancreatic cancer. However, by taking into consideration the pertinent uncertainty (i.e. exact $95 \%$ confidence Interval), in our study the overall frequency of PALB2 mutations detected among breast cancer families with $\geq 1$ case of pancreatic cancer appears to be comparable to the frequency detected in the overall group of BRCAX families (2.1\%) and to those previously reported [1, 3-6]. Thus, if an excess of PALB2 mutations is present in families with occurrences of both breast and pancreatic cancer, this is likely to be modest and detectable only by larger surveys.

Interestingly, we found a PALB2 truncating mutations in one out of two examined individuals who developed both breast and pancreatic cancer. When merged with the data reported by Tischkowitz et al. on patients with the same phenotype [11], this leads to an overall frequency of 2/11 (18.2\%). This suggests that pathogenic mutations of $P A L B 2$ might be relatively frequent in individuals affected with both breast and pancreatic cancer. Further analyses are needed to verify this association.

Finally, in the four identified PALB2-mutated families, a variety of different cancer types were reported (Figure 1). In particular, the proband of family B276, in addition to carcinomas of the small intestine, breast and pancreas, developed multiple colorectal cancers (CRCs), which were diagnosed also in two of her relatives, while a third relative was reported with a gastrointestinal cancer of 
unknown site. Of note, in this family immunohistochemistry and molecular analyses, performed on the proband's intestinal cancers, showed normal expression of DNA mismatch repair (MMR) proteins and no evidence of microsatellite instability (MSI), thus ruling out Lynch syndrome. The proband also tested negative at mutation screening for MUTYH-associated polyposis, while other known syndromic conditions associated with CRC susceptibility were excluded due to the lack of related phenotypes.

Different gastrointestinal cancers, in addition to pancreatic carcinomas, were also reported in the other PALB2 mutation positive families, including two CRCs. Although none of 288 sporadic and 188 familial CRCs from Finland was found to carry the c.1592delT founder mutation [7], an association between PALB2 and CRC was previously suggested by a study reporting a large mutation positive breast cancer family with multiple CRCs [15]. Taken together, these observations support the interest in evaluating the role of $P A L B 2$ in the susceptibility to $C R C$ and, possibly, other gastrointestinal cancers not yet investigated.

In conclusion, our data failed to demonstrate that PALB2 mutations are preferentially associated with breast cancer families with cases of pancreatic cancer, although this might be due to the relative small number of examined individuals. However, screening for PALB2 germline mutation might be recommended in cases affected with both breast and pancreatic cancer. Moreover, our findings, together with previous observations, indicate that $P A L B 2$ mutations might increase the risk of CRC. Searching for PALB2 germline mutations in families with cases of breast cancer and CRC should be considered.

\section{Acknowledgements}

We thank all patients and families who participated to this study. This study was funded by grants from Fondazione Italiana per la Ricerca sul Cancro (Special Project "Hereditary tumors"), Associazione Italiana per la Ricerca sul Cancro (4017), Ministero della Salute (RFPS-2006-3-340203; Extraordinary National Cancer Program 2006, "Alleanza contro il Cancro"; "Progetto Tumori 
Femminili), Ministero dell'Universita' e Ricerca (RBLAO3-BETH), Istituto Superiore di Sanita` (526D/41), Lega Italiana per la Lotta contro i Tumori (progetto 02/12/R/47) and by funds from Italian citizens who allocated the $5 \times 1000$ share of their tax payment in support of the Fondazione IRCCS Istituto Nazionale Tumori, according to Italian laws (INT-Institutional strategic projects ‘5x1000’).

\section{References}

1. Rahman N, Seal S, Thompson D, Kelly P, Renwick A, Elliott A, Reid S, Spanova K, Barfoot R, Chagtai T, Jayatilake H, McGuffog L, Hanks S, Evans DG, Eccles D; Breast Cancer Susceptibility Collaboration (UK), Easton DF, Stratton MR (2007) PALB2, which encodes a BRCA2-interacting protein, is a breast cancer susceptibility gene. Nat Genet 39:165-167

2. Stratton MR, Rahman N. (2008) The emerging landscape of breast cancer susceptibility. Nat Genet $40: 17-22$

3. García MJ, Fernández V, Osorio A, Barroso A, Llort G, Lázaro C, Blanco I, Caldés T, de la Hoya M, Ramón Y Cajal T, Alonso C, Tejada MI, San Román C, Robles-Díaz L, Urioste M, Benítez J. (2009) Analysis of FANCB and FANCN/PALB2 fanconi anemia genes in BRCA1/2-negative Spanish breast cancer families. Breast Cancer Res Treat 113:545-551

4. Cao AY, Huang J, Hu Z, Li WF, Ma ZL, Tang LL, Zhang B, Su FX, Zhou J, Di GH, Shen KW, Wu J, Lu JS, Luo JM, Yuan WT, Shen ZZ, Huang W, Shao ZM. (2009) The prevalence of PALB2 germline mutations in BRCA1/BRCA2 negative Chinese women with early onset breast cancer or affected relatives. Breast Cancer Res Treat 114:457-462 
5. Papi L, Putignano AL, Congregati C, Piaceri I, Zanna I, Sera F, Morrone D, Genuardi M, Palli D. (2009) A PALB2 germline mutation associated with hereditary breast cancer in Italy. Fam Cancer 9:181-185

6. Balia C, Sensi E, Lombardi G, Roncella M, Bevilacqua G, Caligo MA. (2010) PALB2: a novel inactivating mutation in a Italian breast cancer family. Fam Cancer 4:531-536

7. Erkko H, Xia B, Nikkilä J, Schleutker J, Syrjäkoski K, Mannermaa A, Kallioniemi A, Pylkäs K, Karppinen SM, Rapakko K, Miron A, Sheng Q, Li G, Mattila H, Bell DW, Haber DA, Grip M, Reiman M, Jukkola-Vuorinen A, Mustonen A, Kere J, Aaltonen LA, Kosma VM, Kataja V, Soini Y, Drapkin RI, Livingston DM, Winqvist R. (2007) A recurrent mutation in PALB2 in Finnish cancer families. Nature $446: 316-319$

8. Dansonka-Mieszkowska A, Kluska A, Moes J, Dabrowska M, Nowakowska D, Niwinska A, Derlatka P, Cendrowski K, Kupryjanczyk J. (2010) A novel germline PALB2 deletion in Polish breast and ovarian cancer patients. BMC Med Genet 11:20

9. Ghadirian P, Robidoux A, Zhang P, Royer R, Akbari M, Zhang S, Fafard E, Costa M, Martin G, Potvin C, Patocskai E, Larouche N, Younan R, Nassif E, Giroux S, Narod SA, Rousseau F, Foulkes WD. (2009) The contribution of founder mutations to early-onset breast cancer in French-Canadian women. Clin Genet 76:421-426

10. Jones S, Hruban RH, Kamiyama M, Borges M, Zhang X, Parsons DW, Lin JC, Palmisano E, Brune K, Jaffee EM, lacobuzio-Donahue CA, Maitra A, Parmigiani G, Kern SE, Velculescu VE, Kinzler KW, Vogelstein B, Eshleman JR, Goggins M, Klein AP. (2009) Exomic sequencing identifies PALB2 as a pancreatic cancer susceptibility gene. Science 324:217 
11. Tischkowitz MD, Sabbaghian N, Hamel N, Borgida A, Rosner C, Taherian N, Srivastava A, Holter S, Rothenmund H, Ghadirian P, Foulkes WD, Gallinger S. (2009) Analysis of the gene coding for the BRCA2-interacting protein PALB2 in familial and sporadic pancreatic cancer. Gastroenterology $137: 1183-1186$

12. Manoukian S, Peissel B, Pensotti V, Barile M, Cortesi L, Stacchiotti S, Terenziani M, Barbera F, Pasquini G, Frigerio S, Pierotti MA, Radice P, Della-Torre G. (2007) Germline mutations of TP53 and BRCA2 genes in breast cancer/sarcoma families. Eur J Cancer 43:601-606

13. Byrnes GB, Southey MC, Hopper JL. (2008) Are the so-called low penetrance breast cancer genes, ATM, BRIP1, PALB2 and CHEK2, high risk for women with strong family histories? Breast Cancer Res 10:208

14. Slater EP, Langer P, Niemczyk E, Strauch K, Butler J, Habbe N, Neoptolemos J, Greenhalf W, Bartsch DK. (2010) PALB2 mutations in European familial pancreatic cancer families. Clin Genet 78:490-494

15. Foulkes WD, Ghadirian P, Akbari MR, Hamel N, Giroux S, Sabbaghian N, Darnel A, Royer R, Poll A, Fafard E, Robidoux A, Martin G, Bismar TA, Tischkowitz M, Rousseau F, Narod SA. (2007) Identification of a novel truncating PALB2 mutation and analysis of its contribution to early-onset breast cancer in French-Canadian women. Breast Cancer Res 9:R83. 


\section{M1475}

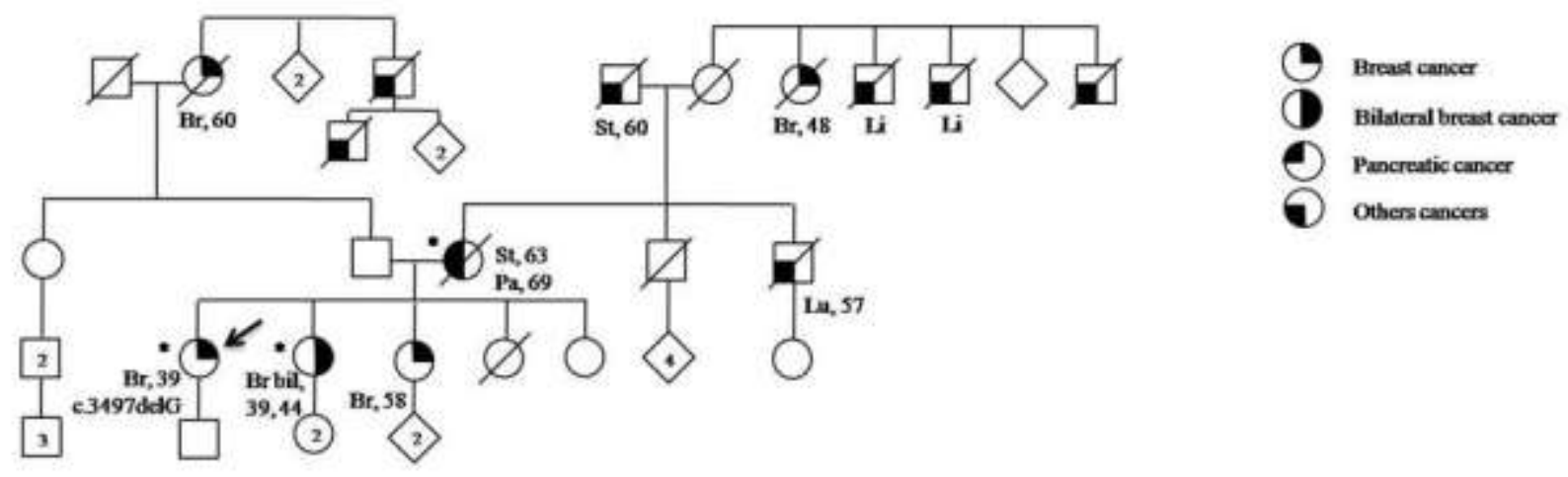

M1203

B276
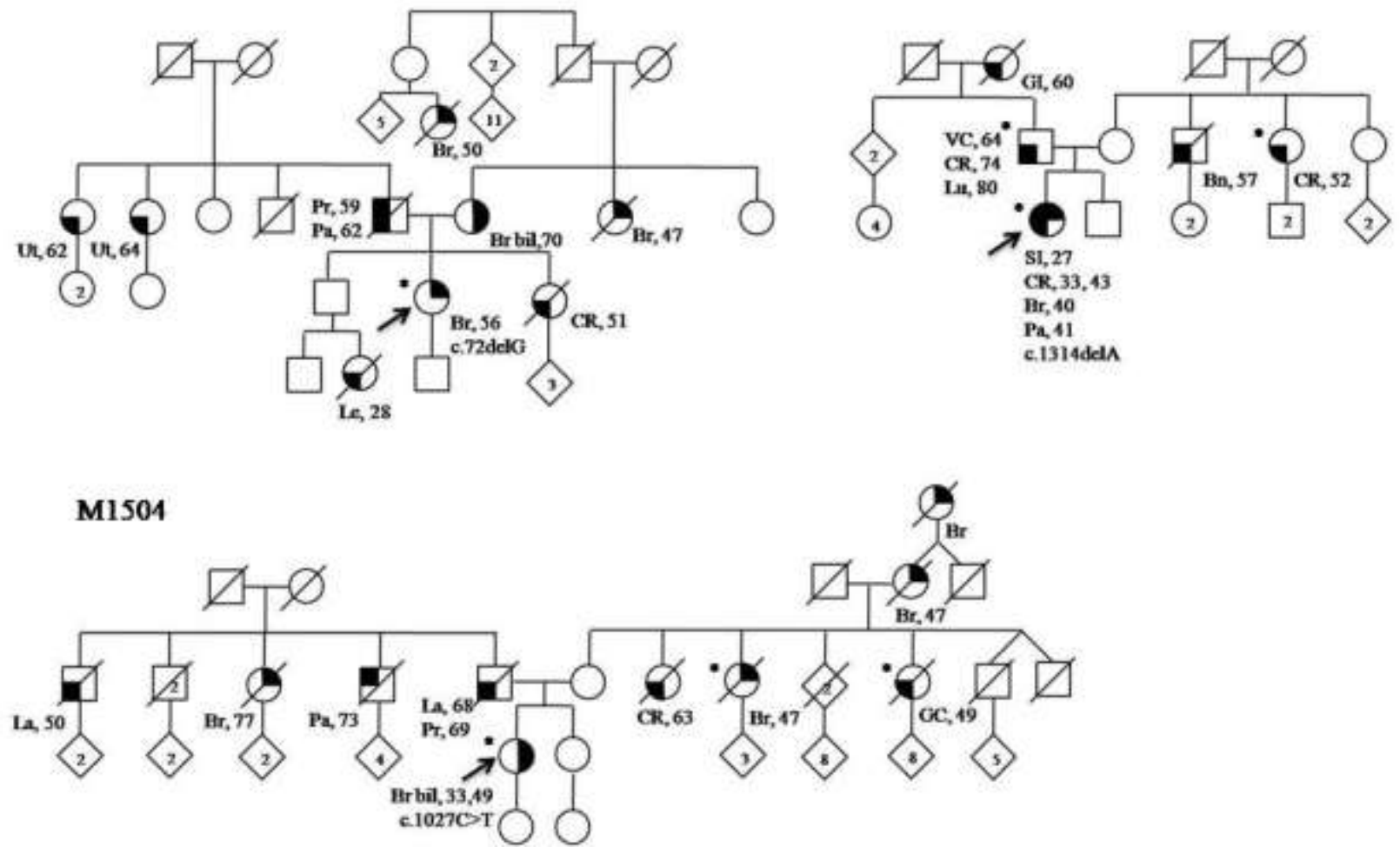

Figure 1. Pedigrees of the four families in which index cases carried a PALB2 truncating mutation. No additional relatives in these families were available for PALB2 mutation testing. Index cases are indicated by arrow and PALB2 mutations are described. Cancer type and age at diagnosis are reported, when known. Individuals affected with documented cancer are indicated by asterisk. Bn, brain cancer; $\mathrm{Br}$, breast cancer; $\mathrm{Br}$ bil, bilateral breast cancer; CR, colorectal cancer; GC, granulosa cell cancer; Gl, gastrointestinal cancer (site unknown); La, larynx cancer; Le, leukemia; Li, liver cancer; Lu, lung cancer; Pa, pancreatic cancer; Pr, prostate cancer; SI, small intestine cancer; St, stomach cancer; Ut, uterine cancer; VC, vocal cords cancer. 